\title{
Cell Thermoregulation: Problems, Advances and Perspectives
}

\author{
A. I. Ibraimov ${ }^{1}$ \\ ${ }^{1}$ Kyrgyz Institute of Balneology and Physiotherapy, Bishkek and Laboratory of Human Genetics, National Center \\ of Cardiology and Internal Medicine, Bishkek, Kyrgyzstan
}

Correspondence: A. I. Ibraimov, Kyrgyz Institute of Balneology and Physiotherapy, Bishkek and Laboratory of Human Genetics, National Center of Cardiology and Internal Medicine, Bishkek, Kyrgyzstan. E-mail: ibraimov_abyt@mail.ru

Received: February 22, 2017

Accepted: March 6, 2017

Online Published: March 14, 2017

doi:10.5539/jmbr.v7n1p58

URL: https://doi.org/10.5539/jmbr.v7n1p58

"All the vital mechanisms ... have only one object - to preserve constant the conditions of the internal environment"... "The stability of the internal environment is the condition for the free and independent life".

Claude Bernard

\begin{abstract}
Thermoregulation at organism level is the well-established fact. The question on possibility of thermoregulation at the cell level remains opened. Based on study of distribution of chromosomal heterochromatin regions (HRs) in various human populations, in norm and at some forms of pathology the hypothesis about thermoregulation existence at the cell level has been presented. The essence of hypothesis of cell thermoregulation (CT) is elimination of the temperature difference between the nucleus and cytoplasm when the nucleus temperature becomes higher than the cytoplasm temperature. The nucleus, in contrast to the cytoplasm, cannot conduct heat directly in the extracellular space, from where the heat is taken by the circulating flow of sap, lymph and blood. Thus, the nucleus can conduct heat only in the cytoplasm. With this, the nucleus has two options for the dissipation of heat surplus: either by increasing its volume or increasing the heat conductivity of the nuclear envelope. As the first option is limited, and the second one is hampered because of thickness of the cell membranes, apparently the higher eukaryotes took advantage of the opportunity of a dense layer of peripheral condensed chromatin (CC) as heat conductor for a more efficient elimination of the temperature difference between the nucleus and cytoplasm. The CC localized between a nucleus and cytoplasm is made of different types of chromosomal HRs. For this reason, $\mathrm{CC}$ is subject to wide variability in population. Obviously, the density of the CC packing depends on the type and quantity of chromosomal HRs in its structure that can affect upon its heat-conducting ability. If the situation is this then we are entitled to expect a new type of variability with all consequences resulting from here.
\end{abstract}

Keywords: cell thermoregulation, Q-heterochromatin, C-heterochromatin, condensed chromatin, human body heat conductivity, multicellularity, human adaptation

\section{Introduction}

More than ten years ago the hypothesis about possibility of thermoregulation existence at a cell level was presented and it was named conditionally as a cell thermoregulation (CT) (Ibraimov, 2003; 2004). For these years, this hypothesis did not receive the direct experimental confirmation at the cell level. However, the indirect methods of CT estimation at level of the whole organism have shown possibilities of such phenomenon existence, and it can have the important theoretical value and practical application (Ibraimov, 2016a, b; Ibraimov et al., 2014a). Some questions related to the experimental verification of the CT hypothesis and prospects of the further researches are discussed in the present work.

\section{Problems}

\subsection{The Cell Thermoregulation Hypothesis}

Based on our original investigations of chromosomal Q-heterochromatin regions (Q-HRs) variability in human populations, as well as on the analysis of existing literary data on the condensed chromatin (CC), structure of interphase nucleus and redundant DNA in the genome of higher eukaryotes, an attempt is made to justify the hypothesis of cell thermoregulation (CT) (Ibraimov, 2003, 2004). 
The data of extensive comparative research on quantitative variability of the chromosomal Q-HRs in human populations have demonstrated that: (1) individuals in a human population differ from each other in the number, location, size and intensity of fluorescence of chromosomal Q-HRs in their genome; (2) there are significant interpopulation differences in the quantitative content of chromosomal Q-HRs in the population genome; (3) these differences proved to be related to features of the ecological environment of the place of permanent residence and not to the racial and ethnic composition of the populations; (4) changes in the amount of Q-HRs in the population genome have a tendency towards a decrease from southern geographical latitudes to northern ones, and from lowaltitude to high-altitude ones; (5) in different age groups the amount of Q-HRs differs; the greatest number of QHRs is characteristic of newborns, while the smallest number is characteristic of elderly subjects; (6) individuals that are capable of adapting to the extreme climate of high altitudes (e.g. mountaineers) and to that of the Far North (e.g. oil industry workers, Yamal peninsula, Eastern Siberia) have extremely low numbers of Q-HRs in their genome; (7) individuals with a lower number of Q-HRs in their genome proved to be prone to alcoholism and obesity, while those with a great number of QHRs to drug addiction (Geraedts \& Pearson, 1974; Muller et al., 1975; Buckton et al., 1976; Lubs et al., 1977; Yamada \& Hasegawa, 1978; Al-Nassar et al., 1981; Ibraimov, 1993; Ibraimov \& Mirrakhimov, 1982a,b,c,d; 1985; Ibraimov et al., 1982; 1986; 1990; 1991; 1997; 2000; 2013; Stanyon et al., 1988; Kalz et al., 2005; Decsey et al., 2006).

As is known, the metabolism of organisms proceeds well only within narrow ranges of internal physical and chemical conditions. Many of the mechanisms that organisms possess serve to maintain this relative internal constancy even when there are large changes in the surrounding environment (homeostasis). Homeostasis depends on an organism's ability to respond to the environment by changing its metabolism.

Virtually, the life, which is known to science, is possible generally at positive temperature, and its highest form mammals - are able to keep a relatively high temperature in the body preserving a very high level of metabolism. Temperature has a fundamental influence in all chemical and biochemical reactions. It influences reaction rates, equilibrium amounts, viscosity, solubility, molecular arrangements and numerous other parameters. Temperature is important for physiological processes as well as cell maintenance and function.

However, by the mechanisms of heat loss the body and individual cells apparently differ. As is known, the external heat flow from a body is performed by way of radiation, conduction, convection and evaporation of water. Apparently, of these mechanisms, the cell, in particular the cell nucleus can use only the heat conduction.

In our opinion, in the elimination of heat surplus from the cell the cytoplasm and nucleus are different. The nucleus, in contrast to the cytoplasm, cannot conduct heat directly in the extracellular space, from where the heat is taken by the circulating flow of sap, lymph and blood. Thus, the nucleus can conduct heat only in the cytoplasm (in case the nucleus temperature, for this or that reason, exceeds the temperature in the cytoplasm). With this, the nucleus has two options for the dissipation of heat surplus: either by increasing its volume or increasing the heat conductivity of the nuclear envelope. As the first option is limited, and the second one is hampered because of a relative constancy of thickness of the cell membranes, apparently the higher eukaryotes took advantage of the opportunity of a dense layer of peripheral condensed chromatin (CC) as heat conductor for a more efficient elimination of the temperature difference between the nucleus and cytoplasm.

\subsection{The Material Basis of Cell Thermoregulation}

We believe that the material basis of cell thermoregulation (CT) consists of those parts of the genome, which is composed mainly of repetitive, non-coding sequences of DNAs. In structural terms, these DNAs occupy the space between the outer surface of the nucleus and the nuclear membrane, and represent chromosomal heterochromatin regions (HRs), which are visible under the microscope as a dense layer of condensed chromatin.

In higher eukaryotes the structural basis of CT consists of chromosomal C-HRs, except for three species of higher primates (Homo sapiens, Pan troglodytes and Gorilla gorilla), in its genome, in addition to the C-HR have Qheterochromatin (Caspersson et al., 1970; Pearson, 1973; 1977; Chiarelli \& Lin, 1972).

All eukaryotes possess repeated DNA sequences in their genomes (Britten \& Kohne, 1968). Highly repetitive regions of chromosomes adopt a heterochromatin structure with distinctive properties and chromatin components (Elgin, 1996). The question of the presence of heterochromatin is similar to that of excess DNA (van Holde, 1989). Since it has been preserved throughout millions of years of evolution, it is reasonable to expect that it has some function. The role that heterochromatin plays in the process is still essentially unknown. This is also reflected in the variety of hypotheses, none of them backed up by solid evidence concerning the possible effects of heterochromatin. These range from the idea that heterochromatin has no function, consisting of 'selfish' DNA, to the assumption that it has an important role in development and evolution (Dover \& Flavell, 1982; John, 1988; Ibraimov, 2015). 
Heitz (1928) invented the term heterochromatin to describe and denote chromosome segments, or in some cases entire chromosomes, that maintains a condensed state during the interphase of the mitotic cell cycle. Heterochromatin represents a large fraction of eukaryotic genomes and is characterized by a high density of sequence repeats that remain condensed through the cell cycle (condensed chromatin). Basic features of chromosomal HRs are the following: they consist, basically, of highly repeated sequences of DNA; HRs occupy quite certain loci of chromosomes having rather great values, namely: areas of centromeres and telomeres, and areas of nucleolar organizers, bearing rRNA genes; replication lability; wide intraspecific variability and, on the other hand, evolutionary fixedness of chromosomal HRs in higher eukaryote genome (in details see ProkofyevaBelgovskaya, 1986; John, 1988; van Holde, 1989; Ibraimov, 2015).

Fundamental feature of chromosomes in higher eukaryotes, including man, is the presence of two evolutionally consolidated types of genetic material: euchromatin and heterochromatin. Euchromatin, the conservative portion of the genome, contains transcribed structural genes, while heterochromatin, the variable portion of the genome, is predominantly composed of non-transcribed repeated DNA sequences. Heterochromatin is universally distributed in the chromosomes of all the eukaryotes - plants, animals and man, accounting for $10 \%$ to $60 \%$ of their genome. Heterochromatin regions (HRs) account for about $15 \%-20 \%$ of the human genome (Micloš \& John, 1979; Verma \& Dosik, 1980; Prokofyeva-Belgovskaya, 1986; John, 1988; Verma, 1988).

To-date two types of constitutive heterochromatin are recognized: Q- and C-heterochromatin (Arrighi \& Hsu, 1971; Hsu \&, Arrighi, 1971; Paris Conference, 1971; 1975). There are several significant differences between them: C-heterochromatin is found in the chromosomes of all the higher eukaryotes, while Q-heterochromatin only in man (Homo sapiens), the chimpanzee (Pan troglodytes) and gorilla (Gorilla gorilla) (Pearson, 1977; Chiarelli \& Lin, 1972). C-heterochromatin regions (C-HRs) are known to be invariably present in all the chromosomes of man, varying mainly in size and location (inversion).

But this does not mean that $\mathrm{CT}$ is exclusively a product of chromosomal HRs. In the chromosomes of higher eukaryotes in addition to HRs there are other tightly packed regular areas, like $\mathrm{G}+$ and $\mathrm{Q}+$ bands, which make up the bulk of the bodies of metaphase chromosomes. In the composition of the chromosomal $\mathrm{G}+$ and $\mathrm{Q}+$ bands there are heterochromatin materials (intercalary heterochromatin). As it is known the telomeric regions of chromosomes also contains heterochromatin.

We also believe that in the removal of heat surplus from a nucleus a nucleolus is actively involved. Thus, some of the chromosomes have nucleolar organizer regions (NORs), which contain ribosomal cystrones. In humans, NORs are localized on acrocentric chromosomes (13-15, 21 and 22). As it is known, NORs, together with chromosomal HRs form the nucleolus bodies. Since chromosomal HRs are in the body and around the nucleolus, there is nothing surprising in the assumption that they due to its high density can promote removal of excess heat from the nucleolus and further to $\mathrm{CC}$ around the nucleus.

Perhaps, it is not coincidentally that the nucleolus is located closer to the periphery of the nucleus. Here we would like to draw attention to one important fact, namely, the nucleolus is associated with the CC and nuclear lamina with short constriction consisting of dense chromatin. Unfortunately, this important structure is paid non-deserved little attention. From our point of view, the constriction serves as an "anchor" that holds the nucleolus to the nuclear lamina and as a "heat conductor" that absorbs excess heat outside the nucleolus. As it is known, the nuclear lamina supports the inner nuclear membrane and helps organize the nuclear contents. Below there is an electron micrograph taken from Wikipedia illustrating the connection of the nucleolus with the dense layer of CC around the nucleus. We added the arrow showing to the constriction between the nucleolus and the nucleus.

\subsection{The Mechanism of Cell Thermoregulation}

Internal sources of heat (thermogenesis) in endothermic organisms are well known: cellular metabolism, muscle contraction and active transport of ions. Thus, the thermal energy, including the excess energy, is produced inside of cells. As a by-product of cell activity, the thermal energy is not used to carry out biologically useful work, and therefore, should be timely removed outside the cells.

There is no known mechanism for a cell to actively dissipate excessive thermal energy. It is a rule to think that diffusion and possibly convection are the primary means to passively remove the heat generated inside the cell (Hochachka, 2003).

This explanation raises a serious objection. The fact is, 'Inside the cell the molecules are mostly associated with polymeric structures (cytoskeletal polymers or membranes) and thus exist in very heterogeneous, solid state environments that alter their behavior dramatically compared to free molecules in test tubes' (Albrecht-Buehler, 1990). As such, highly localized heat sources are expected to create a subcellular temperature gradient. In other 
words, the interacting molecules in the cell do not float freely, as in a test tube with an aqueous solution. Therefore diffusion and convection may not be the primary means to remove the heat generated inside the cell. Therefore, it is necessary to seek other additional mechanisms of removing excess heat from the cell, and in particular of its organelles.

The $\mathrm{CT}$ hypothesis proposed as an attempt to explain rationally the following facts:

1) consistent intra- and interpopulation differences in the quantitative content of chromosomal Q-HRs in human genome are established facts;

2) these differences proved to be related to features of the ecological environment of the place of permanent residence, and not to racial and ethnic composition of the population;

3) the amount of Q-HRs in the genome tend to decrease from southern geographical latitudes to northern ones, and from low-altitude to high-altitude ones;

4) different age groups have different amount of Q-HRs, the greatest number of Q-HRs is characteristic of neonates, while the lowest - of elderly subjects;

5) individuals capable of successfully adapting themselves to the extreme high-altitude climate (e.g. mountaineers) and of the Far North (e.g. oil industry workers of the Jamal peninsula of polar Eastern Siberia) are characterized by extremely low amounts of Q-HRs in their genome;

6) individuals with a lower amount of Q-HR in their genome proved to be prone to alcoholism and obesity, while those with a greater amount of Q-HR - to drug addiction;

7) only the modern human manage to master the whole land of the Earth.

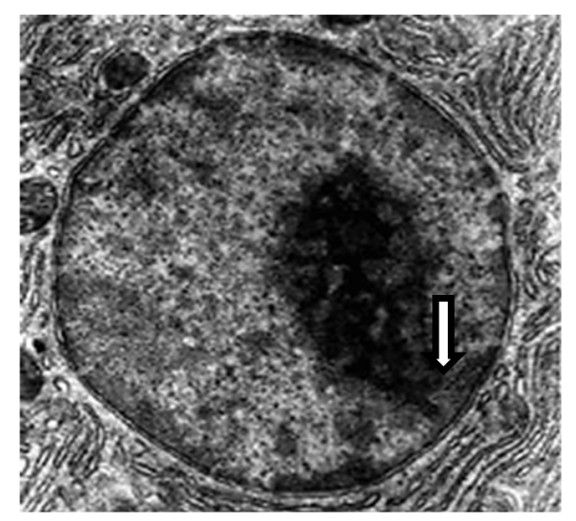

Figure 1. An electron micrograph of a cell nucleus, showing the darkly stained nucleolus. The nucleolus is a discrete densely stained structure found in the nucleus. The nucleolus connection with the condensed chromatin around the nucleus is well seen

Hypothetically, we think of the CT mechanism as follows. For the known in the science reasons, at a certain stage of cell activity the thermal energy excessing the optimal physiological level may be accumulated in the nucleus. Such excessive heat energy is required to remove outside of the nucleus, so it would not harm the normal work of cellular metabolism and of the genetic apparatus. As it is known, high temperature, among other things, has a strong mutagenic effect. Since the nucleus in terms of removing heat surplus, the choice is not great (increase of the own volume and/or density), it is forced to use a dense layer of CC, as the heat removal. Further, the thermal energy, using the cytoskeleton, membrane system and other dense structures of the cytoplasm as a "heat conductor", removed outside the cells in the intercellular space.

Now, we consider the question as surplus metabolic heat is removed from the nucleolus. Apparently, the role of nucleoli in CT is very large; as they are the most "hot" areas in the nucleus in virtue of performed their important functions - synthesis of rRNA. In this process, first of all, chromosomes participating in the formation of the body of the nucleolus are involved. In human these are the acrocentric chromosomes 13-15, 21 and 22 having nucleolar organizer regions (NORs), which contain ribosomal cystrones. As it is known HRs of acrocentric chromosomes, along with the NORs are involved in the formation of the nucleoli body in the nucleus. 
We think that in human the heat surplus removing role of the nucleolus is also performed by a big heterochromatin block on the $\mathrm{Y}$ chromosome in men. It is known for a long time that heterochromatic block of the $\mathrm{Y}$ chromosome is often associated with the nucleolus. Besides, there are observations of contacts of nucleolus with C-HRs of secondary constriction of human chromosomes 1,9 and 16, which do not contain ribosomal cystrones. The frequency of associations of acrocentric chromosomes with chromosome 1 grows with an increase of the size of its C-heterochromatin block (Schmid et al., 1975).

The bulk of these observations encourage the idea that in humans, the basic mass of chromosomal HRs promote elimination of heat surplus, first of all from the nucleolus. As the chromosomal HRs are found in the body and around the nucleolus, it is obvious that they are due to their high density can promote to remove excess heat from the nucleolus to the dense layer of CC around the nucleus.

Now consider the question, how the excess heat is removed from other parts of the nucleus? This question we equate to the question, how is the base level of intracellular heat conductivity inherent in this species supplied. Apparently, the species level of intracellular heat conductivity is provided mainly by chromosomal $\mathrm{G}^{+}$and $\mathrm{Q}+$ bands, as they in normal karyotype are not affected by intrapopulation variability. Besides to $\mathrm{G}+$ and $\mathrm{Q}+$ bands in the process should participate the C-HRs around centromere because they are present in all chromosomes in the normal karyotype.

Finally, what can be said about the molecular mechanism of the $\mathrm{CC}$ dense layer formation around the nucleus on the basis of chromosomal HRs? In this regard, there are no special experimental studies. Theoretically the compactizing effect (f.e., heterochromatinization) of chromosomal HRs could be connected to their nucleotide composition, as they are enriched with highly repetitive sequences of nitrogen bases. But it is not known whether their compactizing effect limited by only HRs segments or the effect spreads to all adjacent areas of chromosomes, as in a case of position effect? Unfortunally, knowledge of the molecular processes involved in these interactions are not available.

\subsection{The Material Basis of Cell Thermoregulation Variability}

Now we shall try to answer the question, how does variability in the level of intracellular heat_conductivity appear on the example of human? Our study of the distribution picture of chromosomal C- and Q-HRs quantities in human populations (Ibraimov \& Mirrakhimov, 1982 a, b, c, d; 1985; Ibraimov et al., 1982; 1986; 1990; 1991; 2013) testify that, apparently, intra - and interpopulation variability in the level of CT create basically the second type of constitutive heterochromatin because of their wide quantitative variability (Ibraimov et al., 2010a,b; 2014a). Besides, it was found that in the human genome there are no significant interpopulation differences in quantitative content of chromosomal C-HRs (Erdtmann, 1982; Ibraimov \& Mirrakhimov, 1982d).

We believe that the material basis of human intra-and interpopulation variability in the level of CT is the amount of chromosomal Q-HRs in his genome. To get some idea of it is necessary to remember the specifics of localization of HRs on the chromosomes in the karyotype.

It is important to note some features of the localization and variability of chromosomal Q-HRs in the karyotype of human. Firstly, Q-HRs is detected on certain loci of only seven autosomes $(3,4,13,14,15,21$ and 22) in both sexes, as well as on the $\mathrm{Y}$ chromosome of males. On the seven autosomes and the $\mathrm{Y}$ chromosome there are only 13 loci where Q-HRs can be detected. Secondly, despite the fact that in the human karyotype there are 13 loci in which Q-HRs can be detected (3cen, 4cen, 13p11, 13p13, 14p11, 14p13, 15p11, 15p13, 21p11, 21p13, 22p11, $22 \mathrm{p} 13, \mathrm{Yq} 12)$, i.e., there could theoretically exist individuals with 25 Q-heterochromatin variants in their genome, but such cases have not as yet been reported. In individuals of a population the number of Q-HRs usually ranges from 0 to 10. Both complete absence and the maximum number of Q-HRs in the genome have no visible phenotypic manifestations. Thirdly, distribution of the number of Q-HRs in individuals of a population is almost normal. Thus, chromosomal Q-HRs is subject to considerably greater variability in any population as compared to C-HRs. About this, Erdtmann (1982) emphasized that 'recent analyses...show a great population and evolutionary stability of C-band homeomorphisms... From interpopulation comparisons, C-band means show a tendency to maintain a constant amount of constitutive heterochromatin'.

Besides, in human on the autosomes 3 and 4, there are areas where can be Q-HRs. At the population level, they make about $30 \%$ of Q-HRs localized on autosomes. Therefore, if the question is put, whether there can be variability in the $\mathrm{CC}$ density around the nucleus, the answer should be positive. However, the basis of intra - and interpopulation variability in humans, after all, is composed of Q-HRs localized on autosomes 13-15, 21 and 22. It is very important that they are all apparently busy with removal of the heat surplus from the nucleolus. Speaking about the variability on CT it is necessary to have in mind the Q-HR localized on the Y chromosome in men. 
Moreover, the size of Q-heterochromatin block on the Y chromosome in the human karyotype and it is subject to wide intra- and interpopulation variability (Ibraimov \& Mirrakhimov, 1985).

And the last, is there a basic level characteristic only for this species, the level of CT? The answer apparently must be positive. In this regard, it should be emphasized that unlike HRs chromosomal G+ and Q+ bands are not affected by hereditary variation and are strictly individual for each species. Constancy of the size, location and alternation on the length of each homolog of $\mathrm{G}+$ and $\mathrm{Q}+$ bands that allows accurately identify all chromosomes in the normal karyotype.

\subsection{Approaches to Monitoring of Intracellular Temperature.}

Acquiring the temperature of a single living cell is not a trivial task. Accurate and noninvasive monitoring of temperature changes in individual cells is a complex technical task. Thankfully, in recent years the situation began to change, new approaches for measuring the temperature of different parts of the cell in vivo began to appear. Although these methods are not developed for the test of a specific biological hypothesis, they seem to be very encouraging, including for verification of the hypothesis of CT.

Thus, several approaches have been proposed to detect cellular temperature response using the emission intensity or lifetime of organic dyes (Chapman et al., 1995; Gota et al., 2009) and transition metal ions (Zohar et al., 1998; Suzuki et al., 2007). These pioneering works were able to provide the average temperature for individual cells. Compared to organic dyes, quantum dots exhibit superior brightness for detection, a broader excitation profile for multiplexing, and better photo stability for long-term studies (Jamieson et al., 2007; Smith et al., 2008; ReschGenger et al., 2008).

Recently, numerous temperature sensors have been developed to meet the urgent demand for measuring temperature in a tiny intracellular space. Among these emerging thermometers, which are based on lanthanide nanoparticles (Vetrone et a., 2010; Peng et al., 2010; Brites et al., 2010;2011; Fisher et al., 2011), dye-coated nanoparticles (Huang et al., 2010), quantum dots (Yang et al., 2010), semiconducting polymer dots (Ye et al., 2011), temperature-responsive polymers (Chen \& Chen, 2011; Gota et al., 2009) and a fluorescent nanogel thermometer (FNT) by combining a thermo-responsive polymer with a water-sensitive fluorophore (Okabe et al., 2012). To the point, the last is the only thermometer that allows the mapping of intracellular temperatures due to its ability to diffuse throughout living cells and its sensitivity to temperature. In terms of sensitivity, the fluorescent molecular thermometers have the ability to distinguish a temperature difference of less than $1{ }^{\circ} \mathrm{C}$.

These methods with different degrees of sensitivity and accuracy demonstrated the existence of a temperature gradient inside a living cell. For example, it is now known that the temperature of the nucleus may be significantly higher than that of the cytoplasm and that the average temperature difference between the nucleus and the cytoplasm was $0.96{ }^{\circ} \mathrm{C}$. Such difference in intensity was significant when the temperature of the medium was $36^{\circ} \mathrm{C}$ (Okabe et al., 2012).

But, unfortunately, none of the aforementioned methods meets the requirements necessary for experimental verification of the CT hypothesis in vivo, namely: a) the measurement of the temperature during the experiment should not be influenced by the physico-chemical characteristics of the nucleus and cytoplasm;; b) should to show the speed of transfer of heat from the nucleus to the cytoplasm in a human cell culture when the temperature the thermostat changed above or below $37^{\circ} \mathrm{C}$; c) all measurements of temperature changes in the nucleus and cytoplasm, regardless of the used method, should, finally, be transformed into the Celsius degrees.

\section{Advances}

\subsection{Experimental Verification of the Cell Thermoregulation Hypothesis.}

It is supposed that any scientific hypothesis can be verified. But what conceivable experimental and natural system can be offered to verify the foregoing idea? It might be reassuring if someone managed to show the following: at the change of temperature in the thermostat above or below $37^{\circ} \mathrm{C}$, the speed of transfer of heat from the nucleus to the cytoplasm in a human cell culture depends, for example, on the amount of chromosomal Q-HRs in the genome of the given individual. Unfortunately, nobody still made this experiment.

The study of the heat conductivity (HC) of non-living physical objects is the advanced part of physics and engineering what cannot be said concerning bodies of living organisms. The HC, from the point of view of physicists is the transfer of energy from the more heated sites of bodies to the less heated as a result of the thermal movement and interaction of micro particles. The HC results in alignment of temperature of a body.

In thermo physics, measurement of heat conductivity of solid bodies (f.e. metal) is carried out by determination of heat conductivity coefficient by a calorimetric method. Transfer of heat occurs through a metal rod, the ends of 
which are placed in a calorimeter with the water taken at temperatures $T 1$ and $T 2(T 1>T 2)$. It is necessary estimation of $\mathrm{HC}$, where decrease of temperature to determine quantity of heat and time transferred through experiment to measure the heat conductivity coefficient of the given metal rod. It is obvious that direct transfer of a method of measurement of the heat conductivity, applied in thermo physics is unacceptable to a human body both for technical and ethical reasons. However, we have tried to approximate to the decision of this problem indirectly, by an estimation of part of a human body. For this purpose, we had to modify the calorimetric method so that it was acceptable to the human body (for more details see Ibraimov et al., 2014a).

Certainly, CT hypothesis should be checked in vivo on the cell level. However, we have not had such opportunity until present. Nevertheless, we have checked this hypothesis on the level of human organism assuming that CT is the basis for heat conductivity of whole cell part of body. These researches showed that individuals in population truly differ from each other in body heat conductivity (BHC) and its level depends on the amount of chromosomal Q-HRs in human genome. In other words, there are some parallels in the distribution of the amount of chromosomal Q-HRs and variability of BHC at the level of human populations (Ibraimov et al., 2014a).

In our lab, these studies were developed in three directions: a) possible selective value of the amount of chromosomal Q-HRs of man in their adaptation to certain extreme environmental factors; b) examining individuals of different sex, age and ethnic groups (Ibraimov \& Tabaldiev, 2007; Ibraimov et al., 2010a,b; 2014a); c) studying of some exclusively human forms of pathology (Ibraimov, 2016a,b). These researches showed that in fact there are differences in the BHC between individuals in population. Results obtained show that individuals in population truly differ from each other in $\mathrm{BHC}$ and its level depends on the amount of chromosomal Q-HRs in human genome.

But some questions still remain unsolved including methodical ones in studying the human BHC variability. In particular, it is still not possible to develop a method to accurately measure the BHC of human, as it is done on homogeneous non-living objects by thermal physicists. Existing methods, at best, only allow assessing the level of human BHC. At best, we can hope for a rough estimate of the level of human BHC: high, medium and low (Ibraimov et al., 2014a).

By studying chromosomal Q-HRs variability in the human populations permanently living in various climaticand-geographic conditions of Eurasia and Africa, in norm and pathology we have obtained the data indicating possible participation of chromosomal Q-HRs in CT (Ibraimov et al., 2010b; 2014b).

Thus, for example, we found that in individuals with obesity the amount of Q-HRs in their genome proved to be extremely low. We once again feel that the reason for this difference lies in the features of cell thermoregulation. Thus, in patients with alimentary obesity and therefore with a low BHC (even assuming that they use the same amount of calories as people with normal weight), we believe that a part of the calories accumulates in the body in the form of adipose deposits due to inadequate heat loss.

The point is that alimentary obesity mainly occurs in people living in temperate, more often in northern but economically developed countries. Surplus heat is not completely removed from the body due to good heat insulation (comfortable habitation and life) and body insulation in the form of modern clothes that are warm but do not adequately contribute to heat loss. If we also take into account the use of high-caloric, easily assimilable food-stuffs, hypodynamia and, possibly, the use of power consuming beverages (alcohol), ineffective heat loss in alimentary obesity become evident.

We suppose that in a human population there is a very great variety in the functioning of the system of energy homeostasis involved in the regulation of food intake, fat stores and energy expenditure related to the amount of Q-HRs in the genome. In individuals with a low BHC, even with a same consumption of food as in people with a normal weight, in comfortable conditions of life, more fat will be deposited than in individuals with a medium or high BHC, as their heat losses are lower due to a lesser BHC.

The problem of alcohol abuse is exclusively human. There are large individual differences in the rate of ethanol metabolism, and a single dose may have widely different effects within a population. Indeed, there has been very strong evidence that ethanol metabolism varies among racial groups (Erikson, 1979). According to data of certain authors, there is a tendency towards an increase in the consumption of strong alcoholic beverages from southern regions to northern ones (Moor, 1964; Keller, 1970; Autkiewicz, 1987). Taking into account the well-known role of alcohol and drugs in metabolism, we have carried out a study in order to detect possible relations between the tendencies of individuals to consume strong alcoholic beverages, as well as drugs, and the amount of chromosomal Q-HRs in their genome taking into account their racial and ethnic features (Ibraimov, 2016a,b; Ibraimov et al., 2010a,b). 
From the data obtained by us, of interest are the following results: 1) alcoholics have the lowest number of Q-HRs in their genome, and they do not differ from each other in all the quantitative characteristics of chromosomal QHRs variability despite their different ethnic affiliation; 2) in the genome of drug addicts the number of QHRs is significantly greater than in controls, especially in subjects abusing in strong alcoholic beverages (Ibraimov, 2016b; Ibraimov et al., 2010b).

We believe that there may be certain relationship between the amount of Q-HRs in the genome, development of alcoholism and drug addiction, especially its relation to the level of human BHC.

The point is that: a) quantitative chromosomal Q-HRs variability only exists in human populations, though this type of heterochromatin is present in the genome of chimpanzee and gorilla; $b$ ) the problem of alcohol abuse and drug addicts is exclusively human; c) notorious propensity to addiction of southerners to drug addicts and northerners and mountaineers to alcoholism still needs further research.

Actually, life and climate in the Far North or at high altitude predisposes, in a certain sense, to drink alcoholic beverages just in order to get a feeling of thermal comfort. But, as we suppose, one and same dose of alcohol in people with different amounts of chromosomal Q-HRs in their genome can lead to different consequences. Thus, people with low BHC, among other factors, to get a sense of thermal comfort are forced to take a relatively large amount of alcohol, and it eventually leads to more severe intoxication with hangover syndrome, than in individuals with normal or great number of chromosomal QHRs. In other words, for warming of the body of individuals with low $\mathrm{BHC}$ requires more alcohol and time than ones with normal or high $\mathrm{BHC}$, even if they have similar physical characteristics.

Drug addicts, i.e., individuals with a high BHC also become accustomed to use drugs because of their wish to get a feeling of thermal comfort, but in this case this "pleasure" is actually due to "narcotic cooling", with consequent emotional or other feelings in drug addicts. Perhaps drug addicts intuitively feel that more pleasure can be received by "cooling" of their body through the drugs than "heating" them with alcohol, since their body having high thermal conductivity liable to rapid heating and cooling.

Some, including the aforementioned facts made us to think about why only people and apes are ill with common cold? These facts are: 1) It is a curious truth that only man and apes suffer from the common cold; 2) Chromosomal Q-heterochromatin is found only in man, the chimpanzee and gorilla, while C-heterochromatin - is found in the chromosomes of all the higher eukaryotes; 3 ) Curiously enough monkeys, unlike the apes, do not seem to be liable to catch common cold; 4) Individuals in population differ in the number of chromosomal Q-HRs (from 0 to 10); 5) The Q-HR on the Y chromosome is the largest in the human karyotype, and its average size is twice greater than all the Q-HRs on autosomes taken together, so the overall amount of Q-HRs in females is as rule lower than in males; 6) Different age groups have different numbers of Q-HRs, the greatest number of Q-HRs is characteristic of neonates, while the lowest - of elderly subjects; 7) Adults typically have two to five infections annually and children may have six to ten colds a year (and up to twelve colds a year for school children), at this, the male individuals are ill more often than the opposite sex representatives; 8) The concept ("Man flu") originated, when many of men suffer from the flu harder than women. Scientific justification is accumulated for the legitimacy existence of the concept of "Man flu" as a more severe form of common cold (Alleyne, 2009; MacRae, 2009); 9) And finally, it is evident that only a proportion of the people who are exposed to cold will develop an infection.

With a view of CT hypothesis, these issues could find satisfactory explanation if to put first such factors as the BHC. We believe that only a human and two apes, being, having in its genome besides C-heterochromatin an additional Q-heterochromatin, are holders of the highly BHC in the animal world (Ibraimov, 2015; Ibraimov et al., 2014a). The greater common cold susceptibility of male individuals may explain the relatively higher heat conductivity of their bodies, in comparison with the opposite sex representatives (Ibraimov \& Tabaldiev, 2007; Ibraimov et al., 2010a). This is related to a well-known fact that the male karyotype has a Y chromosome that contains the largest block of Q-heterochromatin in the human genome. The question why children often ill with common cold than adult individuals in the population can be answered by the fact that different age groups have different numbers of Q-HRs, the greatest number of Q-HRs is characteristic of neonates, while the lowest - of elderly subjects (Buckton et al., 1976; Ibraimov \& Karagulova, 2006; Ibraimov et al., 2014b). In short, different human common cold susceptibility may find their rational explanation in the framework of the CT hypothesis? Namely, it is the level of human BHC that determines how quickly and deeply his body becomes cool at cold, and ultimately the common cold susceptibility of an organism.

Virtually, there is nothing new in the idea that the body of the human should possess some heat conductivity. Nevertheless, it (heat conductivity) has not drawn the attention of nor physicists, neither physiologists for the present as the important physical characteristic of a human body. Apparently, it is connected with known physical 
heterogeneity (in sense, density) of a human body. Besides, direct heat transfer (conduction) has rather small value at redistribution of heat in an organism since the majority of tissues badly conduct heat. Probably that's why, we did not manage to find in the literature not only a special method, but even any attempt to estimate BHC of alive organisms in vivo. On the other hand, basic elements of organ-based physiological thermoregulation are wellknown and now scientists' efforts are directed for research of their complex interactions on molecular level (reviewed in: Romanovsky, 2007).

\section{Perspectives}

Despite the impressive achievements of modern genetics is still not built comprehensive theory of heredity. Such theory must explain the phenomenon of heredity in full, including genetic basis of adaptation, dominance inheritance, the inheritance of acquired characters, regeneration and many groups of facts pertaining to variation, inheritance and development.

For example, Maynard Smith and Szathmary (1997) pointed to some major transitions in biology: the origin of the first eukaryotic cells; the emergence of sex and sexual mode of reproduction; the origin of multicellular plants and animals; the emergence of warm-blooded animals and the origin of modern human, which is difficult to explain within the framework of existing theories of evolution.

In this regard, we believe that some of the answers to these questions can be obtained by studying biology of chromosomal HRs in the genome of higher eukaryotes. Because, it is very difficult to explain the aforementioned and some other biological phenomena in the framework of the "gene-centric" concept, that is, due to the accumulation of favorable mutations and selection of genes. By studying variability of chromosomal Q-HRs in human populations residing permanently in different climatic and geographic conditions of Eurasia and Africa, in norm and pathology, we hoped to understand what, if anything, heterochromatin is doing and why its amounts can vary dramatically, even in organisms that have similar numbers of genes. In the result, we received data evidencing of the possible participation of chromosomal HRs in intracellular thermoregulation. Now the question arises whether can the phenomenon of cell thermoregulation clear the above the problem put by Maynard Smith and Szathmary (1997)? We pre-condition, we do not claim to have received satisfactory answers to these complex problems of modern biology. Here we just want to give some examples of the possible participation of CT in some important processes of evolution and development.

\subsection{Cell Thermoregulation and Origin of Eukaryotic Organisms.}

The issue of how did eukaryotic cell with organelles arise in the first place is still under discussion. The nucleus has no obvious ancestor. Where does it come from? No one seems to know. The nucleus has no evolutionary history or a very rudimentary one. For this reason there are no swiping hypotheses on its ancestry as there are for other eukaryotic organelles such as the mitochondria or the chloroplasts (Schwartz \& Dayhoff, 1978; Dickerson, 1980; Lima-de-Faria, 1983).

It is generally agreed that eukaryotes evolved from prokaryotes. Nevertheless, the answer to the question of how this process occurs is not known. A number of authors have assumed that the line of nucleus genomes of eukaryotes originates from the prokaryote line (or at least from Eubacterium) at very early stages of the cell evolution (Woese \& Fox, 1977a,b; Darnell, 1978; Doolittle, 1980). One suggestion is the endosymbiotic theory of the origin of mitochondria and chloroplast (Margulis, 1971). According to the endosymbiotic theory, the mitochondria and chloroplasts evolved by the incorporation of smaller prokaryotic cells into larger ones. Yet, it should be noted that mitochondria and chloroplasts are not enough to make a prokaryote into a eukaryote. The origin of the nuclear envelope, as well as that of other important structures, including those responsible for nuclear division, still needs to be illuminated (Lima-de-Faria, 1983; 1988).

We suppose that in the origin of the eukaryotes the appearance of the condensed chromatin (CC) was important, which, with time, was covered with a layer of membrane, of endoplasmic reticulum, in this way forming the nuclear envelope. The availability of the nuclear envelope with a dense CC layer from inside makes the following possible: (1) immobilization of chromatin fibers within so called 'chromosome territories', but not as 'spaghetti' in the nuclear sap (otherwise the length of DNA molecules in chromosomes would become tangled or broken were they not segregated into compartments); (2) large genomes have the opportunity to separate in the groups of linkage (chromosomes), and thus they can pass through the mitotic cycle; (3) the existence of chromosomes makes possible a differential condensation, replication and transcription both at the level of the whole chromosome (e.g., inactivation of the second $\mathrm{X}$ chromosome with the female mammals), and its separate parts, by creating the prerequisites for the appearing of specialized cells, tissues, and organs in one organism, and (4) both internal (repair, recombination, rearrangement, modification, restriction) and external (replication, transcription, packaging, 
organized movement) molecular activities of chromosome are realized outside the cytoplasm in a relatively isolated environment (for more see Ibraimov, 2004).

\subsection{Cell Thermoregulation and Sex}

The eukaryotes were the first organisms with sex as we usually understand it. There are numerous hypotheses regarding the origin of sex, but they all are somehow connected with the evolution of genes. We hold the view that the origin of sex is connected with the evolution of the non-coding parts of the genome, and structural genes are associated with the development, mainly, of secondary sexual characteristics (Ibraimov, 2008; 2009; 2010a).

In particular, we suggest that sex as a product of meiosis and specific type of mitosis have appeared as a result of temperature influence upon some stages of cell division. Namely, the low temperature could affect upon the duration of prophase of mitosis. As it is known, in case of a long delay of cell division at the stage of prophase, the homologous chromosomes can conjugate between themselves. In this case, at the anaphase stage not sister chromatids divergence in the daughter cells, as in ordinary mitosis, but the whole parental chromosomes, that is, mitosis turns into meiosis. However, in order that such event should take place, the presence of mitotic chromosomes would be required. There are reasons to believe that the mitotic chromosomes, as well as sex are also the product of a long evolution of non-coding DNAs in eukaryotic genomes (Ibraimov, 2009; 2010a).

If the appearance of sex is the result of complex evolutionary processes in the distant past about which we can only speculate that the mechanisms of sexual differentiation can be tested experimentally. In particular, we postulated that the differentiation of sex is affected by temperature. Namely, the sex differentiation (SD) in animals and human is determined by the amount of constitutive HRs in the chromosomes of the undifferentiated embryonic gonads (UEG) via cell thermoregulation. It is assumed the medulla and cortex tissue cells in the UEG differ in vulnerability to the increase of the intracellular temperature. If the amount of the HRs is enough for efficient elimination of heat difference between the nucleus and cytoplasm in rapidly growing UEG cells the medulla tissue survives. Otherwise it doomed to degeneration and a cortex tissue will remain in the UEG. For artificial regulation of the SD it is proposed to remove a layer of cortex or medulla in the UEG depending on the objective and task of the research (for more see Ibraimov, 2008).

We also are of opinion that the inactivation of one $\mathrm{X}$ chromosome in mammalian cells is associated with CT. As it is known, Lyon (1961) proposed the single-active X-chromosome hypothesis to explain the observation that in the mouse, females heterozygous for X-linked fur color genes are patchy mosaics of two colors. To quote Lyon: “... (1) that the heteropicnotic X-chromosome can be either paternal or maternal in origin in different cells of the same animal; (2) that it is genetically inactivated". According to the Lyon this mechanism provides dosage compensation for X-linked genes because each cell, male or female, has only one X-chromosome that is transcribed.

The point that I am trying to convey is that: a) X-inactivation is not involved in the SD, as Lyon stated (1992); b) $\mathrm{X}$-chromosome is not being inactivated, but it is heterochromatinized in order to compensate the lacking in the female karyotype the largest block of the constitutive HRs in the interest of the CT. Thus, it would be more correct to speak about compensation of the heterochromatin dosage, and not about the dosage (double) of genes (for more details see Ibraimov, 2008).

That CT may be related to inactivation of one $\mathrm{X}$-chromosome in humans is evidenced by such fact as the relatively low level of the BHC in women compared to men at the population level (Ibraimov \& Tabaldiev, 2007; Ibraimov et al., 2010a). This is probably due to the fact that the CC in interphase cells of women do not have the same density as CC in men. Apparently, facultative heterochromatin of the inactivated X-chromosome is still inferior to constitutive heterochromatin on the $\mathrm{Y}$ chromosome on ability to condense (to compactize) $\mathrm{CC}$ in the cells of the female body.

If the CT is indeed related to the becoming and differentiation of a sex, as well as inactivation of one Xchromosome, then, maybe, it is need to reconsider the role of non-coding DNAs and in the appearance specialized cells, tissues and organs in multicellular organisms (for more details see Ibraimov, 2009; 2011; 2012a; 2015).

\subsection{Cell Thermoregulation and Multicellularity}

Many eukaryotes today are multicellular. The emergence of multicellular organisms from single-celled ancestors - which occurred several times, independently in different branches of the eukaryotic tree - is one of the most profound evolutionary transitions in the history of life. However, the genetic changes that accompanied the several origins of multicellularity remain elusive (Ruiz-Trillo et al., 2007).

On the question of whether bacteria often have the traits of a multicellular organism, or whether this is a rare case, the answer given states that most of them, but probably all of them lead the life of multicellular organisms (Chapiro, 
1988). There are really a lot of examples of prokaryote behavior as multicellular organisms. Concerning the issue which is being discussed here, another thing is important: (1) despite the fact that prokaryotes ruled on the Earth for about one billion years, coexisted with eukaryotes for more than 2 billion years, and there is constant contact between the cells of prokaryotes proper, neither now nor before did the prokaryotes form multicellular organisms, and (2) among the multicellular organisms the prokaryotes are not found, despite the fact that in the colonies the specialization of bacterial cells and regulation of protein synthesis are performed by means of signals, i.e. as it is performed in multicellular. We assume that the inability of prokaryotes to form a multicellular organism with a common external cover is attributed to the absence of a mechanism providing maintenance of a relative constancy of temperature in the cells located in the deep parts of body, which is impossible without CC (Ibraimov \& Tabaldiev, 2007).

Therefore, we are of opinion that, perhaps, the dense layer of $\mathrm{CC}$ around the cell nucleus, which is the physical basis of CT, played a decisive role in appearance of multicellular organisms. As we think, for beginnings of macroscopic multicellular organisms, first of all, it is necessary timely to remove the excess metabolic heat from the cells located in the deep compartments of the body (Ibraimov, 2004).

There are also other data, though obtained within the framework of other conceptions, which may testify to our assumption of a possible role of the $\mathrm{CT}$ in the origin of the multicellularity:

(1) Lability of the replication features constitutes a most important peculiarity of HRs, displayed in ontogenesis and phylogenesis. The HR contents in different tissues vary, and are controlled by their underreplication and overreplication (Prokofyeva-Belgovskaya, 1986).

(2) Heterochromatin is formed during early development. It is well known that at the first steps of Drosophila development, the nuclear chromatin is finely dispersed and mitotic chromosomes look like thin filaments. By the blastoderm stage chromocenters and nucleoli are already visible in the nucleus (Mahowald, 1963) and chromosomes can be differentially stained (Vlassova et al., 1991).

(3) In the fertilized egg, the first blastomeres (salmon, trout, mouse and field vole) and in the spermatocytes of Drosophila melanogaster the HRs are completely absent or are of a very small size. Only beginning with stage 4 16 blastomeres, i.e. in mitosis of early embryogeny, the first large blocks of heterochromatin blocks appear (Prokofyeva-Belgovskaya, 1986).

(4) Formation of heterochromatin during early embryonic development in mice has been studied in more detail. It has been demonstrated that at the very beginning (2-4 blastomeres), the interphase nuclei are uniform, and the metaphase chromosomes appear as slim uniform filaments. However, already at the blastocyst stage, G+ bands in the chromosomes are as distinct as in chromosomes of the late embryo fibroblast (Burkholder \& Comings, 1972). In females, $\mathrm{X}$ chromosomes are also heterochromatinized in the blastocyte stage. As the HRs in the chromosome during the embryogenesis process appears only with the appearance of $4-6$ cell blastomeres, i.e. at the stage of actual multicellularity, there are reasons to assume that $\mathrm{CT}$ really could have a relation to the origin of the multicellular organisms.

(5) Examination of Earth's history indicates two major events immediately prior to the origin of complex multicellularity, namely predation (Stanley, 1973) and a sharp increase of oxygen levels (Holland, 2006), that may have contributed to its relatively late appearance.

The latter circumstance is particularly important because excessive heat amount in the body depends on the intensity of cellular metabolism, and it, in turn, is associated with the oxygen concentration. However, in order to maintain a high level of metabolism in the cell without affecting upon its normal functioning, the body, in addition to the CT, should have a mechanism able to withdraw excess heat from the body parts that do not come into direct contact with the external environment. This additional mechanism contributing to the maintenance relative to thermal homeostasis in the body is the circulatory system.

\subsection{Cell Thermoregulation and Circulatory System}

An efficient circulatory system (CS) conducts and distributes heat around the body. In the literature we failed to find a theory or hypotheses that explain the origin of the circulation system, although its role in the life of multicellular organisms is well known.

We are of opinion that the CS has appeared after physical conditions, forcing to move interstitial fluid from one body part to another have been formed in the body of macroscopic animals. Such conditions arise when heat production and heat loss vary considerably in different parts of the body. If the permanent areas with different temperatures (f.e., due to the different intensity of cellular metabolism in different cell types, tissues or organs) have emerged in such organisms, then the extracellular fluid will move from hot departments towards the colder 
parts of the body. Maybe, with the lapse of time, a part of the intercellular space turned into vessels, and the latter, in their turn, obtain ability to shrink to more actively push fluid from one body part to another. Anyway, the phylogeny of the CS evolution in animals show exactly the same picture, which is ended with the formation of the 4 chambered hearts in mammals.

Speaking about the evolution of CS, it is necessary to mention about the occurrence of homoiothermy, more exactly, endothermy. As it is known, birds and mammals are endotherms. Endotherms are animals that warm their bodies mainly from their own metabolism. It is assumed that they became endothermic, because of their ability to maintain a very high level of metabolism intensity and the presence of a 4-chambered heart. However, the level of intracellular metabolism is not determined by ability of animals to produce high-calorie foods or her availability. Ability of cells to withdraw promptly the metabolic heat surplus in the intercellular space is extremely important there. And this is possible only in the presence of a dense CC layer in the interphase cells (see above).

Therefore, we a priori postulate that $\mathrm{CC}$ must be the densest domain in the cells of birds and mammals among higher vertebrates. This confidence is related to the fact that mitotic chromosomes of human give the most clear differential staining (C-, G - and Q-bands), then the other higher primates, and then other mammals. Chromosomes of reptiles and amphibians are differentiate poorly or not at all. By the way, the chromosomes of plants can give only C-bands. Referring to the ability of chromosomes to give differential staining, we mean a well-known fact that $\mathrm{C}+, \mathrm{G}+$ and $\mathrm{Q}+$ bands represent dense areas of mitotic chromosomes, enriched in heterochromatin and other types of repetitive non-coding DNAs, which constitute the physical basis of CC.

We assume that the chromosome segments of the higher eukaryotes have undergone their own evolution in the direction: C-heterochromatin $\rightarrow \mathrm{G}+$ and $\mathrm{Q}+$ bands $\rightarrow$ Q-heterochromatin as response of a cell nucleus for the demand of multicellular organisms in denser packaging of non-coding DNA for the increase of the heat-conducting effect of CC between the nucleus and cytoplasm (Ibraimov, 2003). For example, at a later stage of evolution of the mammals in Africa in the ancestors of three higher primates (Homo sapiens, Pan troglodytes and Gorilla gorilla) besides C-heterochromatin, a new type of constitutive heterochromatin, Q-heterochromatin, appeared. Obviously, this is related to the increase of the metabolism intensity in their organism, and, accordingly, the further improvement of the intracellular thermoregulation. In this case the Q-heterochromatin is not only a new type of constitutive heterochromatin, but possibly an additional 'center of condensation and attraction' for more dense packaging of adjacent inactive chromatin, thus, increasing the heat conducting effect of $\mathrm{CC}$ in the interphase cell of three higher primates (Ibraimov, 2004).

If our arguments really pertain to the actual events in the evolution of animals, then for example, it is not difficult to explain why a crocodile did not become a warm-blooded animal. It is assumed that these large reptiles are coldblooded because they have a 3-chamber heart therefore their arterial blood is poorly oxygenated, and such organism cannot maintain a high level of metabolism. However, anyone unlikely will seriously believe that this drawback can be added more the lack of high-calorie food. It seems to us highly probable that the main reason for a crocodile poikilothermy is specificity of its chromosomes and, like all reptiles; crocodile chromosomes give a bad differential staining. This means that in these cells the CC density is low, which makes difficult the effective transfer of excess metabolic heat from the nucleus to the cytoplasm. Perhaps, a crocodile lies for so long after eating of the next portion of food not because of problems associated with digestion in the digestive organs (f.e., lack of food processing enzymes), and due to the fact that excessive physical activity may cause a risk of overheating of the body in the deep parts of the body. Warm-blooded animals solve this problem by efficient removal of excess metabolic heat using a dense layer of $\mathrm{CC}$ that is; they have more perfect intracellular thermoregulation.

For the present, we do not have any comparative experimental studies on the CC layer density in the cells of cold - and warm-blooded vertebrates. And yet, there is one study that indirectly testifies in favor of our hypothesis. Thus, Bernardi and Bernardi (1986) extensively studied the guanine-cytosine (GC)-rich isochores of cold-blooded (fishes, amphibians and reptiles) and of warm-blooded (birds and mammals) vertebrates. Both the noncoding DNA and the sequences that code for proteins (structural genes) turned out to be much richer in GC in warm- than in cold-blooded animals. Though for the time being we do not know how the GC-rich isochores could influence the appearance of homoiothermy, nevertheless all the above data indicate the existence of a relationship between DNA composition and the appearance of warm-blooded organisms.

Of course, the CS in its present form is the result of a long evolution and without it there would be the long-range transport of thermal energy, chemical signals and metabolic products in the body of multicellular organisms. However, as we believe CS by its appearance, is obliged to CT not in the least (see more in Ibraimov, 2004; Ibraimov \& Tabaldiev, 2007). 
We believe that in the base of these differences are different number of chromosomal HRs in the genome, the biological effect of which is manifested through CT as different BHC. Of course, we are far from a thought that the basis of the aforementioned phenomena lies solely with CT. We just want to emphasize that, CT perhaps, is another factor able to influence upon the evolution of life.

\subsection{Cell Thermoregulation and Human Adaptation.}

Most early human evolution was in the tropics or subtropics and our fossil ancestors occupied semiarid environments, it is not surprising that modern humans are well adapted to rather hot and dry conditions. Then, about 50000 to 100000 years ago our ancestors left the African savannas and began to master climatic zones that differed from those of tropical and subtropical Africa. There the main obstacle met by Homo sapiens as a tropical species was cold, and nevertheless man was able to master all the dry land, including high-altitude regions of the Earth, over a very short historical period. Therefore, for populations to cope with new and challenging habitats there must be an interaction between their genome and their physiological response to allow them to survive a variety of environmental stress. What the 'genetic response' of man to the new ecological challenge was we do not know for sure. However, we have repeatedly noted that man adapted himself to cold and high-altitude hypoxia without the involvement of specific structural genes and managed to do so with the aid of a genetically inert but very mobile (in the sense of hereditary variability) portion of his genome - chromosomal Q-HRs (Ibraimov, 1993; 2010b; 2011a,b; 2015).

According to the principle of temperature homeostasis, heat must leave the body; otherwise, dispersing in tissues, it causes a rise in temperature that is incompatible with life. As heat cannot be used by the body as a source of energy necessary for useful biological work, removal of heat is apparently the most important task of thermoregulation, since only a few degrees are needed to prevent thermal death. If heat emission into the external environment ceases completely, dangerous events of overheating during complete muscular rest may develop in 3-4 hours in man; in mice the corresponding period takes about 40 minutes, while in small birds - only a quarter of an hour. During moderate muscular exercise these periods are several times shorter (Ivanov, 1972). Thus, the organism is not a thermal "machine" and does not use heat to perform physiological work. Therefore, thermoregulation is mainly directed at preventing overheating of the organism, which in terms of biology is more dangerous (Hardy, 1961).

Many studies have shown that prolonged adaptation to cold by increased thermogenesis is hardly possible. Therefore, homoiotherms adapt themselves to cold by increasing thermal insulation, though the problem of removing excess heat arises. Even in polar animals prevention of possible body over heating in winter is the most crucial function of thermoregulation. Allied animal species living under polar and hot climatic conditions do not differ significantly in the intensity of basal metabolism. Polar animals also do not show any significant differences in winter and summer, for it is known that the level of basal metabolism is not a physiologically regulated value and is established by nature. Perhaps that is why people living under different climatogeographical conditions do not differ significantly as to the level of basal metabolism.

Unlike many animal species, man is unstable to live in an extreme cold environment. He is basically a tropical homoiothermic. However, due to various reasons, human populations have to live under conditions of low or high environmental temperature where maintaining the temperature homeostasis is especially difficult. Naturally, all three effectors of thermoregulation systems mobilize: heat production, heat loss and thermoregulatory behavior. Though being important, they cannot be effective at long-term perspective. We suppose that $H$. sapiens, besides those inherent in all mammals possesses an additional but very fine and simple mechanism of thermoregulation. In the present case, in order to preserve temperature homeostasis under different environmental conditions, in addition to physiological, behavioral and biochemical mechanisms such as wide intra population variability by BHC was used. Possibly, for the H. sapiens, BHC diversity is necessary because no single genotype can possess a superior adaptadness in all environments.

From the point of view of the CT hypothesis intracellular thermoregulation mechanisms of human adaptation to various temperature conditions different from climate of Eastern African savannah can be represented schematically in the following way: 1) in the North (where cold is the main limiting human life harmful physical factor of environment) an individual with fewer amount of chromosomal Q-HRs maintains temperature homeostasis in organism more effectively because of low BHC, permitting to preserve additional amount of produced metabolic heat in organism longer and slow down body cooling rate because of external cold; 2) on the North an individual with high BHC, constantly losing by means of conduction additional amount of heat necessary to organism in conditions of cold climate and exposing to relatively fast cooling because of cold, has to produce bigger amount of heat and/or consume more high-calorie food for heat production, which is not always simple and 
healthy, because hunger and vice versa overweight reduce his chances to survive; 3 ) on the South (where environment temperature is higher than body temperature) an individual with low BHC besides his own internal heat production receives additional heat from environment by means of conduction, which, as it is known, is not used in useful physiological work. That is why these individuals' bodies overheat faster and they have to give up heat surplus (through sweating, polypnoe, forced rest, behavioral reactions and etc.) to environment at the cost of significant decrease of physical activity that finally negatively influences on their adaptation to hot climate; 4) individual with big amount of Q-HRs in genome in the South having body with high thermal conductivity perhaps adapts better to high temperature of environment, more effectively leveling temperature differences in different parts of the body and faster directing excess heat flow from organism to environment, including directly the way of heat radiation.

In light of the aforementioned, it is possible rationally explain why the mean number of Q-HRs is considerably lower in the genome of populations living permanently in northern latitudes and high-altitude regions, and in newcomers well adapted to the extreme conditions of high altitude (mountaineers) and the Far North (oil-industry workers-drillers at Western Siberia) as compared to populations living in temperate zones of Eurasia and in lowaltitude subequatorial Africa (Ibraimov, 1993; Ibraimov \& Mirrakhimov, 1982a,b,c,d; 1985; Ibraimov et al., 1982; $1986 ; 1990 ; 1991 ; 1997 ; 2000 ; 2013)$.

While developing the idea about the possible significance of $\mathrm{CT}$ in the adaptation of contemporary man to certain extreme natural factors, we have previously considered the hypothesis on the possible role of Q-heterochromatin in the origin of Homo s. sapiens (Ibraimov, 1993; 2011a,b). According to our hypothesis, since individuals with different amounts of Q-HRs began to appear in the H. sapiens population (as occurs now as well), our ancestors apparently took advantage of this unique feature properly when climate in the African savanna began to change and when they tried to leave it to look for new place to live in as it became necessary to adapt themselves to the new, more inclement environment. Under these conditions advantage is gained by individuals capable of engaging in prolonged and high physical activity. In this case individuals with a lesser amount of chromosomal Q-HRs and accordingly, a lower BHC, who had a certain advantage as concerns survival, could form new populations with a small amount of Q-heterochromatin in the genome, and although the appearance of individuals burdened with a large amount of Q-HRs continued, the pressure of natural selection on such populations was on the whole lower than on the initial ones (for details see Ibraimov, 1993; 2011a,b).

It is hard to say why the ancestors of P.troglodytes and G. gorilla were unable to use the same route. However, the assumption which we feel is likely is the following one: initial Q-HRs frequencies on all the variable loci proved to be high enough to produce of individuals with significantly different numbers of chromosomal Q-HRs and, hence, the appearance of individuals with a various BHC who would be able to survive under unfavorable conditions was quite improbable. In other words, the chimpanzee and the gorilla were initially unable to vary the amount of Q-HRs of their genome as much as man could. The following facts are in favor of this assumption: 1) the range of variability in the number of Q-HRs in the chimpanzee genome is from 5 to 7 (Pearson, 1973; 1977), whereas in the human population it is from 0 to 10, i.e., considerably wider (Yamada \& Hasegawa, 1978; Ibraimov, 1993, 2015); 2) in the gorilla and the chimpanzee, but not in man, a special type of Q-heterochromatin was found, located on the distal ends of certain chromosomes (7, 11,20, and 23 in the gorilla; 20, 21, 22, 23 in the chimpanzee), and that itself makes hard to produce of individuals with different amount of Q-HRs in the karyotype less probable (for details see Ibraimov, 1993; 2010b; 2011a,b; 2015).

\subsection{Cell Thermoregulation, Hairless Skin and Brain Size in Human.}

What is unusual about the human brain is that we are the only largish mammal whose brain size kept pace with our growth in body size. The plausible reason of this phenomenon is his skin, when after having lost its hair it became the largest and almost universal organ of sense. It is assumed that $H$. sapiens became the possessor of the largest brain among the primates after he has lost hair on his skin (Ibraimov, 2007).

Skin is the largest organ in human body, and weighting about $10 \mathrm{~kg}$ in adults its area is more than $1.8 \mathrm{~m} 2$. Skin is a large sense organ, separating and at the same time connecting with the outside world, where receptors, which perceive signals from the external and internal environment are located.

Apparently skin became hairless as a result of evolution of $\mathrm{CC}$ in the genome of the direct ancestors of a modern human. In particular in their karyotypes together with chromosomal C-HRs human chromosome became the carriers of Q-HRs, which have led to significant increase of body heat conductivity. In conditions of tropical Africa, where our ancestors inhabited, availability of skin covered with hair became a serious obstacle in keeping the temperature homeostasis, particularly in dissipation of excessive heat from the organism that finally has led to 
hairlessness. Given this, the heat protection function of the hair cover was taken over by a large amount of subcutaneous adipose tissue.

Many mammals sweat, but human system is the most effective. First, thermal sweat is produced by eccrine glands that pour on to the skin a watery solution with virtually no fats or protein and very little salt. Second, human lose most of their surplus metabolic heat from the body surface, much of it by sweating. Third, our lack of body hair also ensures that sweat provides very efficient cooling as it evaporates from heating skin. The efficient cooling provided by sweating may have been a significant factor in allowing people to run long distances because the high levels of heat produced through running provide a substantial heat load (Baker, 1996).

Naked skin was a result of long series of events, each depending on the other, and each unpredictable and unique. Apparently, the main reasons for appearance of hairless skin were the following factors: 1) increase of BHC because of high Q-HRs and C-HRs content in the genome of the direct ancestor of modern human; 2) quantitative and qualitative changes of the diet composition (Crawford, 1992; Rose \& Marshall, 1996; Horrobin, 1998), which lead to increase of heat production in the organism demanding efficient heat loss from the body for preservation of temperature homeostasis; 3) tropical climate of Africa, where the ancestors of the H. s. sapiens inhabited, had a strong selective influence on such organisms because their bodies have changed towards high heat conductivity and heat production. It is possible that in such conditions the best solution of the thermoregulation problems was modification of skin: loss of hairy cover, increase of its heat dissipation ability by increase of the amount of the eccrine glands, blood vessels, and other changes.

Thus we assume that because of great amount of constitutive heterochromatin in human genome in comparison with other higher primates, the human body became to be distinguished by the greatest heat conductivity. In addition, this important circumstance has led to appearance of hairless skin. We believe that the increase of the human brain size was not the result of drastically changes of the structural genes. Most likely it was the consequence of more ordinary events, such as evolution of constitutive heterochromatin in chromosomes, CT and skin (more details see Ibraimov, 2007; 2012b).

\section{Conclusion}

A change in environmental temperature is one of the most common stresses experienced by a wide range of organisms from bacteria to plants and animals. The response of prokaryotic and eukaryotic systems to heat-shock stress has been investigated widely in a large number of organisms and model cell systems. A sudden temperature up shift poses a serious threat to the integrity of almost all cellular macromolecules. The structure of membrane lipids, DNA, RNA and proteins is altered as the temperature rises. The expression of heat-shock proteins is a universal response found in all living cells (reviewed in: Yura et al., 2000). All organisms from prokaryotes to plants and higher eukaryotes respond to cold shock in comparatively similar manner. Generally, cells respond to cold stress by expression of a small group of proteins, the so termed cold shock proteins (reviewed in: Ermolenko \& Makharadze 2002; Al-Fageeh \& Smales, 2006).

Apart from protein-mediated transcriptional control mechanisms, translational control by RNA thermometers is a widely used regulatory strategy. It is becoming increasingly clear that certain messenger RNAs are not simply a substrate for ribosomes but contain control elements that modulate their own expression in a condition-dependent fashion. Structural changes in such sensory RNAs are induced by specific environmental changes (reviewed in: Narberhaus et al., 2005)

The role of the circulatory systems (CS) has been discussed above in maintaining temperature homeostasis. However, the CS cannot influence directly the temperature inside the cells, as they are linked with the CS indirectly - through the intercellular space. Thus, the CS influence on inner cellular temperature homeostasis is limited and its effect, in general, comes to transferring surplus heat from the intercellular space. That is why it seems that the problem of maintaining the inner cellular temperature homeostasis is solved by cells themselves, and we call it the cell thermoregulation (Ibraimov, 2003; 2004).

It is possible that our attempts to find a common physical denominator in physiological, ontogenetic and pathologic situations that are so different may seem very far-fetched. Moreover, there will be opponents who believe that mechanisms of physiological thermoregulation in man are sufficiently perfect; otherwise he could not master almost all the land on Earth so rapidly and effectively. Indeed, the modern human occupies a more widespread range of environments than any other species, extending from the northern arctic regions to humid tropical forests and arid zones, living at altitudes from sea level to over 5000 meters above sea-level. The range of climatic conditions to which human populations are exposed today closely corresponds to the total variation present on this planet. Life at high altitude imposes environmental stresses - low oxygen pressure, low humidity, cold, and 
increased exposure to high solar radiation. Though, unlike heat or cold stress, high altitude hypoxia can be alleviated only slightly, if at all, by behavioral or cultural adjustments.

As we suppose, during his evolution man, possibly owing to chromosomal Q-HRs, had an additional and very flexible tool to ensure more effective thermoregulation, allowing him to master almost all the oykumene (Ibraimov, 1993; 2010b). In essence, all that was said comes to one simple thought: how does man as a homoiothermic being differ from other mammals as concerns preservation of a constant internal environment the main component of which is temperature homeostasis.

As far as we know, Homo s. sapiens is not only devoid of a more or less large anatomic structure, but also has no protein or enzyme that has no analogue in the animal world. The fundamental structural characteristic of man is the presence of chromosomal Q-HRs in its genome which he has inherited together with the chimpanzee and the gorilla - from one common ancestor. In this context the only difference of $H$. s. sapiens is the wide quantitative Q-HRs variability in his genome.

Apparently, the physiological thermoregulation functions relatively independently from CT as evolutionally new adaptive system (Ibraimov \& Tabaldiev, 2007; Ibraimov et al., 2010a). From our point of view, CT can be the missing link, which should fill the "gap" between the thermoregulation systems, functioning at the molecular level and the whole organism. It is likely that we faced with physiological problem which is a new and alien for classical courses of physiology.

\section{Acknowledgements}

The author is grateful to the Dr. V.V.Popov from the Institute of Mathematics of the National Academy of Science of the Kyrgyz Republic for his help in constructing a thermophisical model for this work.

\section{References}

Albrecht-Buehler, G. (1990). In defense of "nonmolecular" cell biology. Inter Rev Cytol, 120, 191-241.

Al-Fageeh, M. B., \& Smales, C. M. (2006). Control and regulation of the cellular responses to cold shock: The responses in yeast and mammalian systems. Biochem, 397, 247-259.

Alleyne, R. (2009). Men succumb to man flu because women have stronger immune systems, claim scientists, The Daily Telegraph (Published 12 May 2009).

Al-Nassar, K. E., Palmer, C. G., Connealy, P. M., \& Pao-Lo, Y. (1981). The genetic structure of the Kuwaiti population. II. The distribution of Q-band chromosomal heteromorphisms. Hum Gene., 57, 423-427.

Arrighi, F. E., \& Hsu, T. C. (1971). Localization of heterochromatin in human chromosomes. Cytogenetics, 10, 81-86.

Autkiewicz, H. L. (1987). Chinese alcohol use and Hong Kong. Alcoholism, 23, 3-18.

Baker, P. T. (1996). Human adaptations to the physical environments. In S. Jones, R. Martin, \& D. Pilbeam (Eds.), The Cambridge Encyclopedia of Human Evolution (pp. 46-51). Cambridge: Cambridge University Press.

Bernardi, G., \& Bernardi, G. (1986). Compositional constraints and genome evolution. J. Mol. Evol., 24, 1-11.

Brites, C. D. S. (2011). Lanthanide-based luminescent molecular thermometers. New J Chem, 35, 1177-1183.

Brites, C. D. S. (2010). A luminescent molecular thermometer for long-term absolute temperature measurements at the nanoscale. Adv Mater, 22, 4499-4504.

Britten, R. J., \& Kohne, D. F. (1968). Repeated sequences in DNA. Science, 161, 529-540.

Buckton, K. E. (1976). C- and Q-band polymorphisms in the chromosomes of three human populations. Ann Hum Genet, 40, 90-112.

Burkholder, G. D., \& Comings, D. E. (1972). Do the Giemsa-banding patterns of chromosomes change during embryonic development? Exp Cell Res, 75, 269-278.

Caspersson, T., Zech, L., \& Johansson, C. (1970). Differential binding of alkilating fluorochromes in human chromosomes. Exp Cell Res, 60, 315-319.

Chapiro, J. A. (1988). Bacterium as multicellular organism. Sci Amer, 258(6), 46-54.

Chapman, C. F. (1995). The Use of Exogenous Fluorescent-Probes for Temperature-Measurements in Single Living Cells. Photochem. Photobiol, 62, 416-425.

Chen, C.-Y., \& Chen, C.-T. (2011). A PNIPAM-based fluorescent nanothermometer with ratiometric readout. Chem Commun, 47, 994-996. 
Chiarelli, B., \& Lin, C.C. (1972). Comparison of fluorescence patterns in human and chimpanzee chromosomes. Genet Phaenen, 15, 103-106.

Crawford, M. A. (1992). The role of dietary fats in biology: their place in the evolution of the human brain. Nut Rev, 50, 3-11.

Darnell, J. E. Jr. (1978). Implications of RNA-RNA splicing in evolution of eukaryotic cells. Science, 202, 12571260.

Décsey, K., Bellovits, O., \& Bujdoso, G. M. (2006). Human chromosomal polymorphism in Hungarian sample. Int J Hum Genet, 6(3), 177-183.

Dickerson, R. E. (1080). Cytochrome c and the evolution of energy metabolism. Sci Am, 1980; 242(3), 99-110.

Doolittle, W. F. (1980). Revolutionary concepts in evolutionary cell biology. Trends Biochem Sci, 5, 146-149.

Dover, G. A., \& Flavell, R. B. (1982). Genome Evolution. London, Academic Press.

Elgin, S. R. S. (1996). Heterochromatin and gene regulation in Drosophila. Curr Opin Genet Dev, 6, 193-202.

Erdtmann, B. (1982). Aspects of evaluation, significance, and evolution of human C-band heteromorphism. Hum Genet, 61, 281-294.

Erikson, C. K. (1979). Factors affecting the distribution and measurement of ethanol in the body. In E. Majchrowicz, \& E. P. Noble (Eds.), Biochemistry and phamacology of ethanol (pp. 9-23). Plenum Press, New York, London.

Ermolenko, D. N., \& Maharadze, G. I. (2002). Bacterial cold-shock proteins. Cell Mol Life Sci, 59, 1902-1913.

Fischer, L. H., Harms, G. S., \& Wolfbeis, O. S. (2011). Upconverting nanoparticles for nanoscale thermometry. Angew Chem Int Ed, 50, 4546-4551.

Geraedts, J. P. M., \& Pearson, P. L. (1974). Fluorescent chromosome polymorphism: frequencies and segregation in a Dutch population. Clin Genet, 6, 247-257.

Gota, C. (2009). Hydrophilic Fluorescent Nanogel Thermometer for Intracellular Thermometry. J Am Chem Soc, $131,2766-2767$.

Hardy, J. D. (1961). Physiology of temperature regulation. Physiol Rev, 41, 1-521.

Heitz, E. (1928). Das Heterochromatin der Moose. J Jahrb Wisenschs Bot, 69, 762-818.

Hochachka, P. W. (2003). Intracellular Convection, Homeostasis and Metabolic Regulation. J Exp Biol, 206, 2001-2009.

Holland, P. W. H. (1999). Gene duplication: past, present and future. Semin Cell Dev Biol, 10, 541-47

Horrobin, D. F. (1998). Schizophrenia: the illness that made us human. Medical Hypotheses, 50, 269-288.

Hsu, T. C., \& Arrighi, F. E. (1971). Distribution of constitutive heterochromatin in mammalian chromosomes. Chromosoma, 34, 243-253.

Huang, H. (2010). Remote control of ion channels and neurons through magnetic-field heating of nanoparticles. Nat Nanotechnol, 5, 602-606.

Ibraimov A. I., \& Mirrakhimov, M. M. (1982d). Human chromosomal polymorphism. II. Chromosomal Cpolymorphism in Mongoloid populations of Central Asia. Hum. Genet., 60, 8-9.

Ibraimov, A. I. (2003). Condensed chromatin and cell thermoregulation. Complexus, 1, 164-170.

Ibraimov, A. I. (2004). The origin of condensed chromatin, cell thermoregulation and multicellularity. Complexus, 2, 23-34.

Ibraimov, A. I. (2007). The evolution of body heat conductivity, skin and brain size in human. J Hum Ecol, 21(2), 95-103.

Ibraimov, A. I. (2008). Possible mechanism of the sex differentiation and its artificial regulation. Int J Hum Genet, 8(3), 283-290.

Ibraimov, A. I. (2009). Noncoding DNAs and origin of sex. Int J Hum Genet, 9(1), 39-47.

Ibraimov, A. I. (2010a). Noncoding DNAs in Development and Evolution. In M. K. Bhasin, \& C. Susanne (Eds.), Anthropology Today: Trends and Scope of Human Biology (pp. 199-224). Delhi: Kamla-Raj Enterprises. 
Ibraimov, A. I. (2010a). Variability of Human Body Heat Conductivity in Population. I. Methodological and Theoretical Approaches. J Hum Ecol, 32(1), 1-22.

Ibraimov, A. I. (2010b). Chromosomal Q-heterochromatin regions in populations and human adaptation. In M. K. Bhasin, \& C. Susanne (Eds.), Anthropology Today: Trends and Scope of Human Biology (pp. 225-250). Delhi: Kamla- Raj Enterprises.

Ibraimov, A. I. (2010b). Variability of Human Body Heat Conductivity in Population. II. Diseases of Civilization. J Hum Ecol, 32(2), 69-78.

Ibraimov, A. I. (2011a). Origin of modern humans: a cytogenetic model. Hum Evol, 26(1-2), 33-47.

Ibraimov, A. I. (2011b). Evolution without genes. Int J Genet, 3(1), 50 - 61.

Ibraimov, A. I. (2012a). On the origin of sex. GJSFR (C), 12(8) (Ver. 1.0), 1-6.

Ibraimov, A. I. (2012b). Evolution of human skin color and thermoregulation. Int J Genet, 4(3), 111-115.

Ibraimov, A. I. (2013). Chromosomal Q-heterochromatin polymorphisms in 3 ethnic groups (Kazakhs, Russians and Uygurs) of Kazakhstan. Int J Genet, 5(1), 121-124.

Ibraimov, A. I. (2014a). Human Chromosomal Q-heterochromatin Polymorphism and Its Relation to Body Heat Conductivity. Int J Genet, 6(1), 142-148.

Ibraimov, A. I. (2014b). Chromosomal Q-heterochromatin and age in human population. J Mol Biol Res, 4(1), 1-9.

Ibraimov, A. I. (2015). Heterochromatin: The visible with many invisible effects. Global J Med Res, (C), 15(3), $7-32$.

Ibraimov, A. I. (2015). The Evolution of Material Basis of Evolution. $J$ Adv Biol, 8(2), 1596-1606.

Ibraimov, A. I. (2016a) Chromosomal Q-Heterochromatin Polymorphism in Patients with Alimentary Obesity. Biol Med (Aligarh), 8, 275.

Ibraimov, A. I. (2016b) Chromosomal Q-heterochromatin Regions in Alcoholics and Drug Addicts. Biol Med (Aligarh), 8, 346.

Ibraimov, A. I., \& Karagulova, G. O. (2006). Chromosomal Q-heterochromatin regions in individuals of various age groups. Int J Hum Genet, 6(3), 219-228.

Ibraimov, A. I., \& Tabaldiev, S. K. (2007). Condensed chromatin, cell thermoregulation and human body heat conductivity. J Hum Ecol, 21(1), 1-22.

Ibraimov, A. I., Karagulova, G. O., \& Kim, E. Y. (1997). Chromosomal Q-heterochromatin regions in indigenous populations of the Northern India. Ind J Hum Genet, 3, 77-81.

Ibraimov, A. I. (1982). Human chromosomal polymorphism. I. Chromosomal Q-polymorphism in Mongoloid populations of Central Asia. Hum Genet, 60, 1-7.

Ibraimov, A. I. (1986). Human chromosomal polymorphism. IX. Further data on the possible selective value of chromosomal Q-heterochromatin material. Hum Genet, 73, 151-156.

Ibraimov, A. I. (1990). Chromosomal Q-heterochromatin regions in native highlanders of Pamir and Tien-Shan and in newcomers. Cytobios, 63, 71-82.

Ibraimov, A. I. (1991). Chromosomal Q-heterochromatin regions in the indigenous population of the Northern part of West Siberia and in new migrants. Cytobios, 67, 95-100.

Ibraimov, A. I. (1993). The origin of modern humans: a cytogenetic model. Hum Evol, 8(2), 81-91.

Ibraimov, A. I., \& Mirrakhimov, M. M. (1982a). Human chromosomal polymorphism. III. Chromosomal Qpolymorphism in Mongoloids of Northern Asia. Hum Genet, 62, 252-257.

Ibraimov, A. I., \& Mirrakhimov, M. M. (1982b). Human chromosomal polymorphism. IV. Q-polymorphism in Russians living in Kirghizia. Hum Genet, 62, 258-260.

Ibraimov, A. I., \& Mirrakhimov, M. M. (1982c). Human chromosomal polymorphism. V. Chromosomal Qpolymorphism in African populations. Hum Genet, 62, 261-265.

Ibraimov, A. I., \& Mirrakhimov, M. M. (1985). Q-band polymorphism in the autosomes and the Y chromosome in human populations. InA. A. Sandberg (Ed.), Progress and Topics in Cytogenetics. The Y chromosome. Part A. Basic characteristics of Y chromosome (pp. 213-287). Alan R. Liss, Inc., New York. USA. 
Ibraimov, A. I., Karagulova, G. O., \& Kim, E. Y. (2000). The relationship between the Y chromosome size and the amount of autosomal Q-heterochromatin in human populations. Cytobios, 102, 35-53.

Ivanov, K. P. (1972). Bioenergetics and temperature homeostasis. "Nauka", Leningrad

Jamieson, T. (2007). Biological Applications of Quantum Dots. Biomaterials, 28, 4717-4732.

John, B. (1988). The biology of heterochromatin. In R. S. Verma (Ed.), Heterochromatin: Molecular and Structural Aspects (pp. 1-147). Cambridge University Press, Cambridge, New York, New Rochelle, Melburn, Sydney.

John, B., \& Micloš, G. L. G. (1979). Functional aspects of satellite DNA and heterochromatin. Int Rev Cytol, 58 , $1-114$.

Kalz, L. (2005). Polymorphism of Q-band heterochromatin; qualitative and quantitative analyses of features in 3 ethnic groups (Europeans, Indians, and Turks). Int J Hum Genet, 5(2), 153-163.

Keller, M. (1970). The great Jewish mystery. British J Addict, 64, 287-296.

Lima-de-Faria, A. (1983). Molecular Evolution and Organization of the Chromosomes. Elsevier, Amsterdam, New York, Oxford.

Lima-de-Faria, A. (1988). Evolution without Selection. Form and function by autoevolution. Elsevier. Amsterdam, New York, Oxford.

Lubs, H. A. (1977). Racial differences in the frequency of Q- and C-chromosomal heteromorphism. Nature, 268, 631-632.

Lyon, M. F. (1961). Gene action in the X-chromosome of mouse. Nature, 190, 372-374.

Lyon, M. F. (1992). Some milestones in the history of X chromosome inactivation. Annu Rev Genet, 26, 17-28.

MacRae, F. (2009). Man flu is not a myth: Female hormones give women stronger immune systems. Daily Mail (Published 13 May 2009).

Mahowald, A. P. (1963). Ultrastructural differentiations during formation of the blastoderm in the Drosophila melanogaster embryo. Dev Biol, 8, 1-16.

Margulis, L. (1971). Symbioses and evolution. Sci Amer, 225(2), 48-57.

Maynard Smith, J., \& Szathmary, E. (1995). The Major Transitions in Evolution. Oxford: Freeman/Spektrum.

McKenzie, W. H., \& Lubs, H. A. (1975). Human Q and C chromosoma1 variations: distribution and incidence. Cytogenet Cell Genet, 14, 97-115.

Micloš, G. L. G., \& John, B. (1979). Heterochromatin and satellite DNA in man: properties and prospects. Am J Hum Genet, 31, 264-280.

Moor, R. (1964). Alcoholism in Japan. Quart. J Stud Alcohol, 25, 142-150.

Müller, H. J. (1975). Chromosome polymorphism in a human newborn population. II. Potentials of polymorphic chromosome variants for characterizing the idiograms of an individual. Cytogenet Cell Genet, 15, 239-255.

Narberhaus, F., Waldminghaus, T., \& Chowdhury, S. (2006). RNA thermometers. FEMS Microbiology Reviews, $30(1), 3-16$.

Okabe, K. (2012). Intracellular temperature mapping with a fluorescent polymeric thermometer and fluorescence lifetime imaging microscopy. Nat Commun, 3, 705.

Paris Conference and Supplement. (1971, 1975). Standartization in human cytogenetics. Birth Defects: Original Article Series, XI, 1-84. The National Foundation, New York.

Pearson, P. L. (1973). The uniqueness of the human karyotype. InT. Caspersson, \& L. Zech (Eds.), Chromosome identification techniques and application in biology and medicine (p. 145). New York, London. Academic Press.

Pearson, P. L. (1977). Pattern of bands, polymorphism and evolution of primates. In J. J. Yunis (Ed.), Molecular structure of human chromosomes. Acad. Press.

Peng, H. (2010). Luminescent europium (III) nanoparticles for sensing and imaging of temperature in the physiological range. Adv Mater, 22, 716-719.

Prokofyeva-Belgovskaya, A. A. (1986). Heterochromatic Regions of Chromosomes (in Russian). Moscow, Nauka.

Resch-Genger, U. (2008). Quantum Dots Versus Organic Dyes as Fluorescent Labels. Nat Methods, 5, 763-775. 
Romanovsky, A. A. (2007). Thermoregulation: some concepts have changed. Functional architecture of the thermoregulatory system. Amer J Physiol-Regul Integr Comp Physiol, 292, R37-R46.

Rose, L., \& Marshall, F. (1996). Meat eating, hominid sociality, and home bases revisited. Curr Anthropol, 37, 307-338.

Ruiz-Trillo, I. (2008). A phylogenomic investigation into the origin of metazoa. Mol Biol Evol, 25, 664-72.

Schmid, M., Vogel, W., \& Krone, W. (1975). Attraction between centric heterochromatin of human chromosomes. Cytogenet Cell Genet, 15, 66-80.

Schwartz, R. M., \& Dayhoff, M. O. (1978). Origin of prokaryotes, mitochondria, and chloroplasts. Science, 199, 395-403.

Smith, A. M. (2008). Bioconjugated Quantum Dots for in vivo Molecular and Cellular Imaging. Adv Drug Delivery Rev, 60, 1226-1240.

Stanley, S. M. (1973). An ecological theory for the sudden origin of multicellular life in the late Precambrian. Proc Natl Acad Sci USA, 70, 1486-89.

Stanyon, R. (1988). Population cytogenetics of Albanians in the province of Cosenza (Italy): frequency of Q and C band variants. Int $J$ Anthropol, 3(1), 14-29.

Suzuki, M. (2007). Microscopic Detection of Thermogenesis in a Single HeLa Cell. Biophys J, 92, L46-L48.

van Holde, K. E. (1989). Chromatin. New York, Springer.

Verma, R. S. (Ed). (1988). Heterochromatin. Molecular and Structural Aspects. Cambridge Univ. Press. Cambridge, New York, Sydney.

Verma, R. S., \& Dosik, H. (1980). Human chromosomal heteromorphisms in American blacks. I. Structural variability of chromosome 3. J Hered, 71, 441.

Vetrone, F. (2010). Temperature sensing using fluorescent nanothermometers. ACS Nano, 4, 3254-3258.

Vlassova, I. E. (1991). Constitutive heterochromatin in early embryogenesis of Drosophila melanogaster. Mol Gen. Genet, 229, 316.

Woese, C. R., \& Fox, G. E. (1977a). The concept of cellular evolution. J Mol Evol, 10, 1-6.

Woese, C. R., \& Fox, G. E. (1977b). Phylogenetic structure of the prokaryotic domain: the primary kingdoms. Proc Nat Acad Sci USA, 74, 5088-5090.

Yamada, K., \& Hasegawa, T. (1978). Types and frequencies of Q-variant chromosomes in a Japanese population. Hum Genet, 44, 89-98.

Yang, J.- M., Yang, H., \& Lin, L. (2010). Thermogenesis detection of single living cells via quantum dots. IEEE 23rd Int Conf Microelectromech S (MEMS), 963-966.

Ye, F. (2011). Ratiometric temperature sensing with semiconducting polymer dots. J Am Chem Soc, 133, 81468149.

Yura, T., Kanemor, M., \& Morita, M. T. (2000). The heat shock response: regulation and function. In: G Storz, R Hengge-Arons (Eds.): Bacterial Stress Responses. Washington, DC: ASM Press, pp. 3-18.

Zohar, O. (1998). Thermal Imaging of Receptor-Activated Heat Production in Single Cells. Biophys J, 74, 82-89.

\section{Appendix}

1. Qualitative model of a possible heat-loss effect of chromosomal Q-HRs in the nucleus.

We will show that chromosomal Q-HR in the nucleus increases the speed of heat loss from the cell nucleus. From the physical point of view it is clear that one and the same substance has a higher thermal conductivity when it is in a denser state. Q-HR is the densest areas of the nucleus and consequently their thermal conductivity should be higher than in other chromatins.

Let us suppose that all the Q-HR is localized on the inner surface of the nuclear membrane. In order to create a simple thermophysical model let us "spread" mentally the Q-HR along the entire nuclear membrane with $\alpha$ thick layer. Let us assume that the linear size of the nucleus is equal to $r$, the Q-HR thermal conductivity rate is equal to $\lambda_{1}$, while the mean thermal conductivity rate of the rest of the nucleus is $\lambda_{2}$. According to our hypothesis $\lambda_{2}<\lambda_{1}$. We also believe that heat production occurs in the entire nucleus. 
Assuming that initially $(t=0)$ the state is not stationary, then during $t>0$ this state will relax to stationary one. We feel that on the boundary between Q-HR and the nuclear membrane temperature is set and constant. The mathematical model will be described in more detail below.

Let us first present the results of studying this model. With reasonable limitations of the initial distribution of temperature $(T)$ in the cell nucleus, the dependence of temperature in it upon time with $t>0$ is described by the expression

$$
T=\theta_{1}(x, t) e^{p t}+\theta_{2}(x),
$$

where

$$
p=p_{1}=-\frac{\pi^{2} \lambda_{1}}{4 \rho_{1} c r^{2}}\left(1-2 \frac{\lambda_{2} a}{\lambda_{1} r}\right)
$$

if the nucleus contains Q-HRs, and

$$
p=p_{2}=-\frac{\pi^{2} \lambda_{1}}{4 \rho_{1} c r^{2}}\left(1-2 \frac{a}{r}\right)
$$

if there are no Q-HRs in it.

In the present formulas: $x$ - spatial co-ordinate, $\rho_{l}$ - density, $c$ - mean specific thermal capacity of the nucleus. It is assumed that $\lambda_{1} / \rho_{1}=\lambda_{2} / \rho_{2}$, where $\rho_{2}$ - the mean density of the nucleus beyond the area of Q-HR. Function $\Theta_{2}$ depends on the spatial co-ordinate $x$ and describes the distribution of temperature in the nucleus in $t \rightarrow \infty$, i.e., after establishment of the stationary state.

The main result: $\left|p_{1}\right|>\left|p_{2}\right|$, i.e., the presence of Q-HRs increases the speed of heat loss from the nucleus and therefore increases the speed of its cooling and the speed of relaxation towards a stationary state after sudden cooling of the cytoplasm.

Let us describe the used mathematical model. This model contains two one-dimensional, nonstationary, heterogeneous equations of thermal conductivity taking into account heat production in the nucleus. In its physical essence it describes the compound rod, the left part of which $a$ long corresponds to Q-HR, while the right one ( $r$ a) long models the rest of the nucleus. On the left border of the left rod (i.e., on the boundary between Q-HR and the nuclear membrane) the temperature is constant. On the contact of two rods (i.e., between Q-HR and the rest of the nucleus) are continued temperature and heat flow density. On the right border of the right rod (i.e., in the centre of the nucleus) density of heat flow is equal to zero. Initial condition corresponds to nonstationary state.

The problem of relaxation of the initial state towards a stationary one is solved by using the Laplace transformation as concerns variable $t$, after which the boundary problem for the system of ordinary differential equations is solved. Subsequent reverse Laplace transformation results in quadratures such as

$$
T(x, t)=\int \tau(x, p) e^{p t} d p
$$

The contour of reverse transformation integration is ordinary: vertical straight line on the complex plane $p=p^{\prime}+$ $p$ ". Function $\tau(x, p)$ contains denominator

$$
\Delta(p)=\cos (q a) \cos (q r)+\frac{\lambda_{2}}{\lambda_{1}}[\sin (q a) \sin (q r)],
$$

where $\mathrm{q} 2=\rho_{l} c p / \lambda_{l}$. The smallest as to the modulus root $p 1$ of the equation $\Delta(p)=0$ in the assumption that $a<<r$ is presented above (2). Residue in the corresponding function pole $\tau(x, p)$ results in (1). Similarly, we found a solution (3) to $\lambda_{1}=\lambda_{2}$ (absence of Q-HRs in the nucleus).

Let us write out the initial equations of the problem solved, boundary and initial conditions:

$$
\begin{array}{ll}
\rho_{1} c \frac{\partial T_{1}}{\partial t}=\lambda_{1} T_{1}^{\prime \prime}+J_{1}, & 0<x<a, \\
\rho_{2} c \frac{\partial T_{2}}{\partial t}=\lambda_{2} T_{2}^{\prime \prime}+J_{2}, & a<x<r,
\end{array}
$$

hatches indicate the second derivative for $x$, 


$$
\begin{gathered}
T_{1}(x, 0)=\tau_{1}(x), \quad T_{2}(x, 0)=\tau_{2}(x), \\
T_{1}(0, t)=T_{0}=\text { const }, \\
T_{2}^{\prime}(r, t)=0, T_{1}(a, t)=T_{2}(a, t), \\
\lambda_{1} T_{1}^{\prime}(a, t)=\lambda_{2} T_{2}^{\prime}(a, t),
\end{gathered}
$$

$J_{l}, J_{2}=$ const - heat source densities.

\section{Copyrights}

Copyright for this article is retained by the author(s), with first publication rights granted to the journal.

This is an open-access article distributed under the terms and conditions of the Creative Commons Attribution license (http://creativecommons.org/licenses/by/4.0/). 